NBER WORKING PAPER SERIES

\title{
COST SHOULD BE NO BARRIER: AN EVALUATION OF THE FIRST YEAR OF HARVARD'S FINANCIAL AID INITIATIVE
}

\author{
Christopher Avery \\ Caroline Hoxby \\ Clement Jackson \\ Kaitlin Burek \\ Glenn Poppe \\ Mridula Raman
}

Working Paper 12029

http://www.nber.org/papers/w12029

\author{
NATIONAL BUREAU OF ECONOMIC RESEARCH \\ 1050 Massachusetts Avenue \\ Cambridge, MA 02138 \\ February 2006
}

\begin{abstract}
We, the authors, could not have completed this study without inspiration, expertise, and a great deal of data from Harvard's Office of Admissions and Financial Aid, which has shown unswerving commitment to a enlarging the scientific understanding of prospective applicants, their academic and other accomplishments, and their financial needs. We particularly wish to acknowledge the help and inspiration from William R. Fitzsimmons, Dean of Admissions and Financial Aid to Students in Harvard College; Marlyn McGrath Lewis, Director of Admission for Harvard College; Elizabeth Yong, Director of Information Services, Office of Admissions and Financial Aid; and Janet Irons, Associate Director of Financial Aid. We also wish to thank Stephen Broughman and Steven Gorman of the National Center for Education Statistics for help with, respectively, the Private School Survey and the National Assessment of Educational Progress. Patrick Florance, Digital Cartography Specialist of the Harvard College Libraries helped us greatly with geocoding. We also thank the following staff at state departments of education who helped us with obtaining data on secondary schools in the United States: Bob Beecham, Nebraska; Matt Hesser, Oklahoma; Tom Deeter, Iowa; James Griffiths, Michigan; Judy Snow, Montana; Helmut Feifs, North Carolina; Mindy Crain-Dorough, Louisiana; Kathi Slaughter, Iowa; Tony Moss and Sherrill Martinez, Kansas; Nancy Walker, West Virgina; Doris Steward, Denis Airola, and Charles Watson, Arkansas; Marylou Mandell, Georgia; Jennifer Weber and David Gall, South Dakota. The authors wish to emphasize that, although the people we have listed above provided data and answered numerous questions, we prepared this paper independently and did not consult them on methods or results. We are solely responsible for the content of the paper. The views expressed herein are those of the author(s) and do not necessarily reflect the views of the National Bureau of Economic Research.
\end{abstract}

(O2006 by Christopher Avery, Caroline Hoxby, Clement Jackson, Kaitlin Burek, Glenn Poppe, Mridula Raman. All rights reserved. Short sections of text, not to exceed two paragraphs, may be quoted without explicit permission provided that full credit, including $\odot$ notice, is given to the source. 
Cost Should Be No Barrier: An Evaluation of the First Year of Harvard's Financial Aid Initiative Christopher Avery, Caroline Hoxby, Clement Jackson, Kaitlin Burek, Glenn Poppe, Mridula

Raman

NBER Working Paper No. 12029

February 2006

JEL No. I20, I21, I22, J24, L3

\begin{abstract}
$\underline{\text { ABSTRACT }}$
This paper evaluates the first year of Harvard's Financial Aid Initiative, which increased aid and recruiting for students from low income backgrounds. Using rich data from the Census and administrative sources, we estimate family incomes for the vast majority of plausible applicants from the U.S. We find that the Initiative had a significant effect almost entirely because it attracted a pool of applicants that was larger and slightly poorer. It appears that very similar standards of admission were used for this group as had been used in previous years. This group, once admitted, enrolled at a rate very similar to that of previous years. Thus, there are a greater number of low income students in the Class of 2009 than in the Class of 2008 simply because more well-qualified, low income students applied. Put another way, the initiative did not create a new form of affirmative action-rather, there was an untapped supply of able, low income students. Many apparently qualified students still do not apply, and a disproportionate share of these "missing applicants" come from high schools that have little or no tradition of sending applications to selective private colleges. Targeted outreach to such "one offs" - that is, students who are one of only a few qualified students from their school in recent years - may be a way for selective private colleges to increase their income diversity.
\end{abstract}

Christopher Avery

Harvard University

John F. Kennedy School of Government 79 John F. Kennedy Street

Cambridge, MA 02138

and NBER

christopher_avery@ksg.harvard.edu

Caroline Hoxby

Department of Economics

Harvard University

Cambridge, MA 02138

and NBER

choxby@harvard.edu
Clement Jackson

Graduate School of Arts and Sciences

Harvard University

Kaitlin Burek

Harvard College

Glenn Poppe

Harvard College

Mridula Raman

Harvard College 


\section{EXECUTIVE SUMMARY}

This paper evaluates the effect of the first year of Harvard's Financial Aid Initiative. In addition to the data from admissions and financial aid, we compile information on the family background, neighborhood, and high school of every student who applied, was admitted, or enrolled. We also compile this information for every student who appears in the "Search File" that The College Board sends to Harvard because the Search File approximates the pool of plausible applicants. Our detailed background information, much of which is at the level of Census block where student resides, allows us to estimate family incomes for students who do not apply. By using the estimates to supplement actual income reports, we gauge how Harvard is doing relative to the population of plausible applicants. We focus on students who reside in the U.S.

We find that the Financial Aid Initiative had a significant effect on the Class of 2009, almost entirely because it drew in a group of applicants that was much larger and somewhat poorer. It appears that the Admissions Office applied very similar standards to this group as it had applied in previous years and that students, once admitted, enrolled at a rate very similar to that of previous years. Thus, there are a greater number of low income students in the Class of 2009 than in the Class of 2008 simple because more wellqualified, low income students applied. Put another way, the initiative did not create a new form of affirmative action-rather, there was an untapped supply of able, low income students.

Specifically, the number of applicants to Harvard rose by a dramatic 15 percent between the Classes of 2008 and 2009. Moreover, the extra applicants were disproportionately likely to be low income: the share who qualify for the Initiative (family income of $\$ 60,000$ or less) rose from 12.3 percent to 14.5 percent. After admissions and enrollment decisions, 16.5 percent of the Class of 2009 qualified for the Initiative, up from 14.9 percent for the Class of 2008.

Although the first year of Initiative induced students to apply who might otherwise not have, many apparently qualified students still do not apply. Many of the "missing applicants" come from high schools that have little or no tradition of sending applications to Harvard. Thus, for years to come, a key way for Harvard and similar schools to increase the income diversity of their classes will be raising the probability of application among qualified students who do not currently set their sights on selective private colleges. This may be achievable through targeted outreach to students who are "one offs"- that is, students who appear in the Search File but are one of only a few qualified students from their school in recent years. In addition, the Financial Aid Initiative (and others like it at competing institutions) may motivate low income students to achieve at a higher level so that, eventually, the pool of plausible applicants will contain more students from families of modest means. 


\section{Why An Initiative on Financial Aid?}

In the early months of 2004, Harvard created a Financial Aid Initiative to encourage students from families with low to moderate incomes to apply to The College. ${ }^{1}$ This paper evaluates the results of the first full year of the Initiative, which culminated in the entry of freshmen in the fall of 2005 for the Harvard Class of 2009.

\section{A. Financial Aid at Harvard Prior to the Initiative}

In 2004, when the Initiative was announced, Harvard had for many years practiced need-blind admissions and provided very substantial financial aid to students whose families could not afford the college's full costs. For instance, in the 2003-04 school year, two-thirds of students received financial aid, and the average aid package was $\$ 26,700$. This package meant that the average student on financial aid paid about 30 percent of the total cost of attendance, which was $\$ 37,928$ in 2003-04. ${ }^{2}$ Students from lower income families paid a smaller share. For example, the average family with an income of $\$ 40,000$ or below paid $\$ 2,300$ (about six percent of the total cost of attendance). Prior to the Initiative, the Harvard Admissions Office also made considerable effort - via recruiting trips, information sessions all over the country, letters to prospective applicants, and an array of admissions material (both print and online) - to reach out to students from disadvantaged backgrounds. When the admissions staff assessed an application from a student appeared to be disadvantaged, they adjusted their expectations in light of the fact that such students often have limited opportunities to take advanced placement classes, engage in extracurricular activities, and obtain counseling and help with their applications. Nevertheless, in 2004, The College was concerned about whether it was sufficiently accessible to talented students from families to low to moderate incomes. Its concerns were in four areas, and the Financial Aid Initiative was designed to address each concern.

First, although the contributions asked of low income families were modest relative to Harvard's cost of attendance, they might nevertheless have posed an obstacle to such families. A contribution of $\$ 2,300$ represented about seven percent of the aftertax income of a family with income of $\$ 40,000$ in $2004 .^{3}$ A family struggling to make ends meet might find it difficult to give up such a share of their disposal income.

Second, some analysts believed that Harvard's aid plan was sufficiently opaque to be off-putting for low to moderate income families. That is, families could not easily foresee what they would be asked to contribute and many may have foregone the opportunity to find out. It was surmised that a simpler, more salient plan might better convey Harvard's commitment to making The College accessible to talented students from all backgrounds.

\footnotetext{
${ }^{1}$ The Financial Aid Initiative was officially announced on February 28, 2004. Documents describing the announcement and the initiative may be found on the website of the Harvard Gazette, especially the following link: http://www.news.harvard.edu/gazette/2004/03.04/01-finaid.html.

${ }^{2}$ The total cost of attendance includes tuition, room, board, fees, and other charges. Tuition was $\$ 26,066$ in the 2003-04 school year.

${ }^{3}$ The tax liability (including FICA taxes) in 2004 was approximately $\$ 8,000$ for a family with $\$ 40,000$ of earnings and two dependents, one of whom was college-aged. The source is TAXSIM, National Bureau of Economic Research, 2005.
} 
Third, low to moderate income students often come from households, schools, and neighborhoods in which information about selective private colleges is scarce. Information about Harvard and its accessibility may not reach them, and their counselors and parents may be less likely to encourage them to apply. In some cases, a student attends a school that has almost no experience sending applicants to colleges like Harvard, so that there are no former students or counselors to credibly convey knowledge about the application, aid, and college experience to prospective applicants.

The final, related problem is that the schools that low to moderate income students attend often lack the curriculum to fully prepare their most talented students for the competitive application process and academic requirements of colleges like Harvard. Some schools offer such modest academic and extracurricular opportunities that even a student who takes advantage of every opportunity may find herself with little advanced coursework and limited experience in leadership, athletic, and cultural positions. As a result, applicants from low income backgrounds may appear to be less meritorious than they truly are. Even if admissions staff attempt to adjust for disadvantaged students' paucity of opportunities, their adjustments may be insufficient for students who attend secondary schools that are unfamiliar to the Admissions Office. Logically, we expect the adjustments to be calibrated best for schools, such as some inner-city magnet schools, that regularly send applications from meritorious, disadvantaged students. (Below, we return to this point.)

\section{B. What the Financial Aid Initiative Did}

Harvard's Financial Aid Initiative had one or more features that addressed each concern described above. The initiative stated explicitly that parents with incomes below $\$ 40,000$ would not be expected to contribute at all to the cost of a Harvard College education. Also, the initiative stated that parents with incomes between $\$ 40,000$ and $\$ 60,000$ would be expected to contribute less $(\$ 1,250$ less on average) than previously. The announcement of zero cost for families with incomes lower than $\$ 40,000$ was particularly salient and easy to understand. As a result, it received considerable coverage in the media. Although public knowledge of the policy may grow somewhat in future years, it is the one feature of the Initiative that was fully fledged and widely understood by applicants to the Class of 2009.

The second feature of the Financial Aid Initiative was increased effort to reach out to students from low to moderate income families. The Admissions Office focused new recruiting efforts on students likely to benefit from the initiative. These efforts took a variety of forms including school visits, letters from the admissions office, telephone calls from current Harvard students, and outreach by Harvard alumni in their local areas. Indeed, in a related study, we (the authors) are putting together indicators that will help admissions offices, including Harvard's, identify students from disadvantaged backgrounds in a more accurate, multidimensional way. The increase in recruiting efforts was intended to expand the size and diversity of the pool of applicants from which Harvard draws. It is nature of outreach to improve with practice-contacts generate contacts, successful targeting hones future targeting. Thus, we should expect the prospective class of 2009 to reflect only a fraction of the long-term results that will accrue to increased recruiting effort by the Admissions Office. 
The third feature of the Financial Aid Initiative addressed the issue that low income students might be at a disadvantage in the admissions process because they lack some of the academic and extracurricular opportunities enjoyed by students from higher income families. In previous years, the Admissions Office gave special attention to students from particular schools known to have limited extracurricular activities and to students whose applications made it obvious that they come from disadvantaged backgrounds. In 2004, the Admissions Office initiated a systematic procedure for identifying disadvantaged students and assessing their applications in the light of these disadvantages. Essentially, the goal is to make accurate adjustments for differences in opportunities - so that students on how they will do at Harvard — even when a student attends a high school that is initially unfamiliar to the admissions staff. Like recruiting efforts, such analysis is only likely to improve with practice. Thus, we expect the class of 2009 to reflect only a fraction of the long-term consequences of admissions officers' intensifying their scrutiny of the effects of coming from a disadvantaged background.

The fourth and final feature of the Financial Aid Initiative is a summer program for promising students from disadvantaged backgrounds. The program will directly relieve some of the deprivation in the academic and extracurricular environments in which low income students often grow up. The summer program, still in its infancy, is very unlikely to have affected students in the Class of 2009, so an evaluation of its effects must be left for future research.

In short, by comparing Harvard admissions immediately before and after the enactment of the Financial Aid Initiative, we are mainly evaluating the effect of increased aid for families with incomes less than $\$ 60,000$. We are also evaluating the new recruiting and admissions efforts, but we expect our results to understate the long-term effects of such efforts. We wish to emphasize that, in the very long-term, policies like the Financial Aid Initiative may have effects that dwarf the short-term effects we study. For instance, if all selective private colleges were successfully to advertise greater accessibility to low income students, then low income students might be motivated to prepare themselves academically for education at a selective college.

\section{Our Analysis}

In this paper, we evaluate how the Financial Aid Initiative affected the composition and size of the pool of students who applied to Harvard, the composition of the group of students who were admitted to Harvard, and the composition of students who enrolled in Harvard's Class of 2009. In each case, we are interested in whether the students were more likely to be drawn from low to moderate income families, the intended targets of the Initiative. Although we are mainly interested in direct measures of family income, we are also interested in other indicators of students' socioeconomic diversity. In particular, we examine parents' education, parents' occupations, and the neighborhoods in which families reside. We also investigate whether the Initiative has drawn students from secondary schools that have little or no "track record" sending applicants or matriculants to The College.

Our method is to compare the Class of 2008, who applied before the Initiative

was announced, and the Class of 2009, who went through the admissions process with the 
Initiative in place. Because the initiative was announced before the Class of 2008 had made decisions about whether to enroll, it might have affected their matriculation decisions. ${ }^{4}$ However, the announcement could not have affected their decision to apply for admission or their decision to apply for financial aid.

In this paper, we employ three main types of data. First, we use "Search Files" created by The College Board for Harvard's use. The Search Files contain information on individual students who-based on their admissions test scores, self-reported grade point averages, and other criteria - have a non-negligible probability of being admitted to Harvard. Roughly speaking, the search files may be thought of as the universe from which Harvard can draw plausible applicants, at least among Americans. ${ }^{5}$

Our second type of data is individual application and financial aid records, which we obtained through the generosity of Harvard's Office of Admissions and Financial Aid. We can only identify family income precisely for students who were admitted to Harvard and who applied for financial aid. For this reason, we have a third type of data: rich socio-demographic and administrative data for every census block and school (public and private) in the United States. The key element of our analysis is that we match each student to the census block in which his family resides and to the school that he attends. A census block is a small area - a neighborhood in metropolitan areas. To put things in perspective, the average census block in the United States contains 50 households, and there are hundreds of census blocks in a typical metropolitan school district. ${ }^{6}$ Once we know the census block where a student lives and the school he attends, we can use information from those sources to estimate family income for students who are in Harvard's Search Files or group of applicants. ${ }^{7}$ Our income estimates are reasonably accurate for the range of incomes at which students apply for financial aid. ${ }^{8}$ For instance, we might predict that a family's income is $\$ 90,000$ when it is truly $\$ 100,000$, but we are

\footnotetext{
${ }^{4}$ For this reason, we tried to obtain data that would allow us to compare the matriculation decisions of the Class of 2007 and the Class of 2009. Unfortunately, this proved to be impossible.

${ }^{5}$ The Search File is created by The College Board and sent to the Harvard Admissions Office in the spring of each year. The file includes addresses for more than 60,000 rising high school seniors whose test scores are high enough to make them plausible candidates for admission to Harvard. Approximately $60 \%$ of the U.S. applicants and approximately $75 \%$ of U.S. students enrolling at Harvard appear in the Search File for the year in which they apply. Most other U.S. students who enroll at Harvard will have appeared in a previous year's Search File, most likely because they take the SAT test early and are thus "searched" in the year prior to the year in which they will apply.

6 A census block is the smallest geographic entity for which the Census tabulates data. It is often an actual block in urban areas but larger geographically in rural areas (though not necessary larger in people). Blocks are usually bounded on all four sides by visible features such as roads. Population-by-race and other useful data are available at the block level. Household income and parents' education is available at the block group level, which we use when block level data are not available.

${ }^{7}$ For addition detail on our income estimation, we refer you to a related paper on which we are currently at work.

${ }^{8}$ For a number of reasons - including the emphasis of this paper, data availability, and an explicit wish to avoid the appearance that the Harvard Admissions Office is obtaining information with which they might price discriminate among mid- to high-income applicants - we do not attempt to estimate very accurately the income for students who are above the range of those who routinely require financial aid. Thus, readers should assume that statistics associated with incomes above $\$ 120,000$ are rough calculations only. Moreover, we should note that we did not provide an income estimate to the Harvard Admissions Office for any student unlikely to qualify for the financial aid initiative.
} 
very unlikely to predict that the family is poor when it really has income of $\$ 100,000{ }^{9}$ Keep in mind that we use actual income data whenever they are available. We use estimated income only to complete the picture for students for whom we have no data from the Office of Financial Aid. ${ }^{10}$

Our analysis focuses on students whose families reside in the United States. This is for two reasons. We make this restriction because there is no one accepted way to convert foreign incomes into American equivalents, and the results would be sensitive to how individual foreign currencies were converted. Moreover, the Financial Aid Initiative was clearly motivated by the circumstances of U.S. residents. The rich in many countries have incomes lower than $\$ 60,000$, but they enjoy lifestyles and local educational opportunities that ensure that they are not deprived in the way envisioned by the Initiative. Finally, we cannot get socio-demographic information on the neighborhoods and schools of students who reside in foreign countries. In short, any picture we drew of students who reside abroad would necessarily be sketchy and would probably be misleading.

\section{Does the Class of 2009 Contain More Students from Low Income Families that the Class of 2008?}

The most straightforward method for assessing the success of the Financial Aid Initiative is to compare, for the classes of 2008 and 2009, the share of students who come from families with incomes below $\$ 40,000$ or between $\$ 40,000$ and $\$ 60,000$. We describe these students as "qualifying" for the Financial Aid Initiative, although it is important to remember that the Initiative was not actually announced until the class of 2008 had applied.

We put all income amounts, including the thresholds of $\$ 40,000$ and $\$ 60,000$, into 2004 equivalents. ${ }^{11}$ We do this so that the Class of 2009 does not automatically appear to be richer than the previous class, as it would if we ignored the general rise in incomes that occurred between the two years.

We find that 6.6 percent ( 97 of 1459) of the students in the class of 2008 were from families below the $\$ 40,000$ threshold, but such students made up 7.9 percent (117 of 1478 ) of the class of 2009. Similarly, 8.2 percent (119 of 1459) of the students in the class of 2008 were from families with incomes between $\$ 40,000$ and $\$ 60,000$, but such students made up 8.7 percent (128 of 1478) of the Class of 2009 . In short, there was an increase of 1.8 percent ( 29 students) in the two low-income categories for the Class of

\footnotetext{
9 In fact, there are no students for whom predicted income is less than $\$ 40,000$ and actual income is $\$ 100,000$ or greater. Among students with predicted income below $\$ 60,000$, only 0.2 percent have actual incomes of $\$ 100,000$ or greater.

${ }^{10}$ We have also done all of the analysis in this paper using estimated family income for all students. By doing this, we eliminate any biases associated with the fact that actual income is available for a selected group where the selection is not random but determined by application and admissions conduct. Because we get results that are very similar for the purposes of evaluation and interpretation to the results we show here, this paper does not present the analysis based solely on estimated incomes. However, the results are available from the authors.

11 Specifically, we use the change in per capita income for the state in which the student resides to inflate 2003 incomes into equivalent 2004 incomes.
} 
2009. The increases are shown in Figure 1 and detailed in Table 1. These numbers are consistent with, but not identical to, Admission Office reports about the Initiative because we have excluded international students and because we used state-by-state changes in family incomes method to convert all income amounts into 2004 equivalents. This is the most exact method of making the two income years comparable.

Figure 1: Students who Qualify for the Financial Aid Initative in the Classes of 2008 and 2009

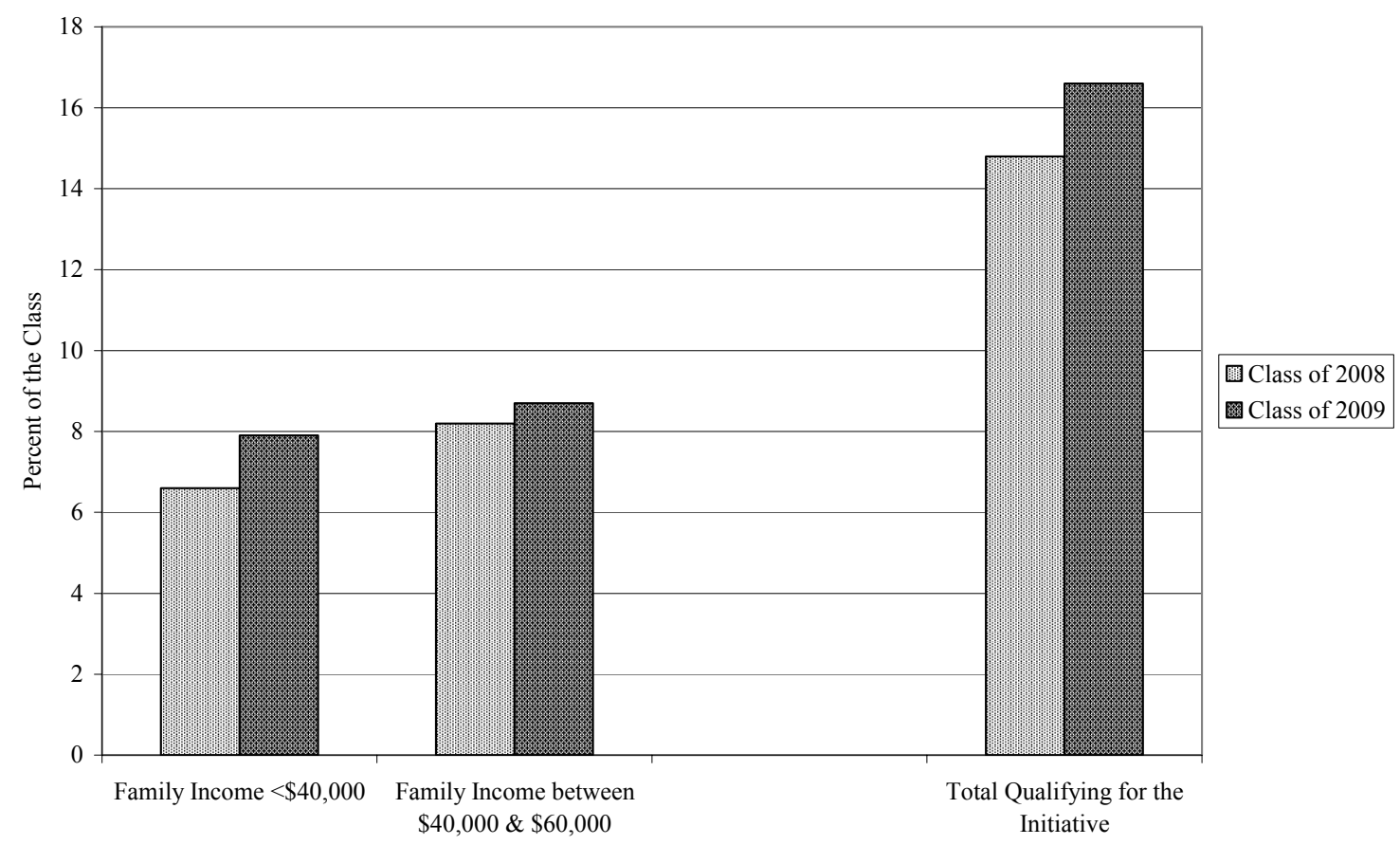

Table 1:

Students who Qualify for the Financial Aid Initiative in Classes of 2008 and 2009

\begin{tabular}{|l|c|c|}
\hline & Class of 2008 & Class of 2009 \\
\hline Share with Family Income $<\mathbf{\$ 4 0 , 0 0 0}$ & 97 of $1,459(6.6 \%)$ & 117 of $1,478(7.9 \%)$ \\
\hline $\begin{array}{l}\text { Share with Family Income between } \\
\mathbf{\$ 4 0 , 0 0 0} \& \mathbf{\$ 6 0 , 0 0 0}\end{array}$ & 119 of $1,459(8.2 \%)$ & 128 of $1,478(8.7 \%)$ \\
\hline Total Share Qualifying for the Initiative & 216 of $1,459(14.8 \%)$ & 245 of $1,478(16.6 \%)$ \\
\hline
\end{tabular}

Notes: This table contains the same information as Figure 1. All incomes are put into 2004 equivalents so that the comparison of the Classes of 2008 and 2009 could be on an even basis. Only students whose families reside in the U.S. are included. The differences between the classes are not statistically significant at the 90 percent confidence level.

A. What Accounts for the Larger Number of Low Income Students in the Class of 2009?

It is important to understand the source of the larger number of low income students in the Class of 2009. Were there more qualified low income students in the high 
school graduating class than in the previous year? Did a higher percentage of qualified low income students apply to Harvard? Did the Admissions Office favor low income students in admissions decisions (relative to the previous year)? Were low income students more likely to matriculate for the Class of 2009, conditional on having been admitted? To answer these questions one at a time, we compare four separate populations of students for these two years: 1) potential applicants in The College Board Search File; 2) applicants to Harvard; 3) students admitted to Harvard; 4) students matriculating to Harvard.

\section{i. Potential Applicants}

We found that the income distribution of prospective students in The College Board Search Files (whom we will call "searched" students for clarity) was approximately the same for the two years once we took account of the overall rise in incomes from one year to the next. Column 1 of Table 3 below lists the income distribution for the first of the two years. Similarly, the distributions of searched students in terms of neighborhood and type of high school were approximately the same for the two years. This suggests that the high school graduating classes and the pool of potential applicants to Harvard was largely the same in the two years. This should be no surprise because the criteria by which students were put into the search file were approximately the same.

\section{ii. The Applicants}

We found that applicants for the Class of 2009 were significantly more likely to students who qualify for the Financial Aid Initiative (family income less than $\$ 60,000$ ) than applicants for the Class of 2008. Harvard's applications jumped dramatically from 16,821 for the Class of 2008 to 19,321 for the class of $2009,{ }^{12}$ so our analysis compares the percentages of applicants in each income category across the two years.

Specifically, 4.6 percent of the applicants for the Class of 2009 came from families with incomes below $\$ 40,000$, whereas 3.6 percent of the applicants for Class of 2008 came from such families. Also, 9.9 percent of the applicants for the Class of 2009 came from families with incomes between $\$ 40,000$ and $\$ 60,000$, but 8.7 percent of the applicants for Class of 2008 came from such families. These differences are shown in Figure 2 and Table 2 and are statistically significant.

Table 2 also shows the mean and several percentile values for the family incomes of applicants for the Classes of 2008 and 2009. Indeed, 2009 applicants had lower mean family incomes in $2009(\$ 120,015)$ than in $2008(\$ 124,111),{ }^{13}$ and lower incomes at each percentile value throughout the distribution.

\footnotetext{
${ }^{12}$ We do not include international applicants in our analysis, so these numbers are lower than the total number of applications in each year - X for the Class of 2008 and $Y$ for the Class of 2009.

${ }^{13}$ The income amounts given here are in 2004 equivalents, for both classes.

${ }^{15}$ To create the adjusted admission rates for the Class of 2008, we divide the admissions rate for each income range for applicants for the Class of 2008 by the ratio of the admissions rates for the two classes. This adjustment produces the admissions rate that would result from an equal proportional decline for every income range. Since the adjusted admission rates for the Class of 2008 are approximately the same in every income range as the actual admission rates for the Class of 2009, it appears that the admission rates did in fact decline by a similar proportion in each group when applications increased for the Class of 2009.
} 
Figure 2: Applicants who Qualify for Financial Aid Initiative, Classes of 2008 and 2009

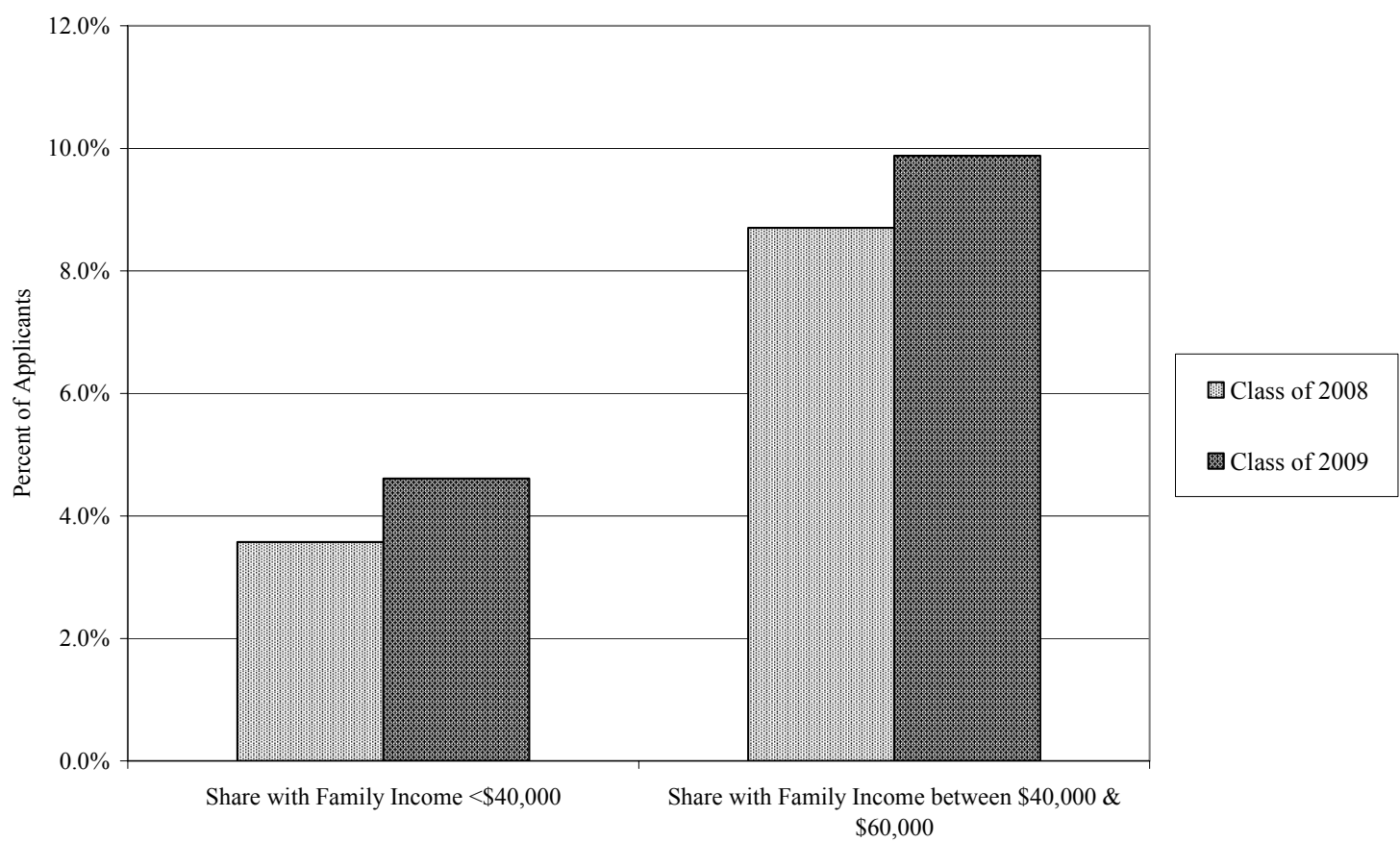

Table 2:

Family Incomes, Applicants to the Classes of 2008 and 2009

\begin{tabular}{|c|c|c|}
\hline & Class of 2008 & Class of 2009 \\
\hline Share with Family Income $<\$ \mathbf{4 0 , 0 0 0}$ & $\begin{array}{c}601 \text { of } 16,817 \\
(3.6 \%)\end{array}$ & $\begin{array}{l}891 \text { of } 19,321 \\
(4.6 \%)^{*}\end{array}$ \\
\hline $\begin{array}{l}\text { Share with Family Income between } \$ 40,000 \\
\& \$ 60,000\end{array}$ & $\begin{array}{c}1,463 \text { of } 16,817 \\
(8.7 \%)\end{array}$ & $\begin{array}{c}1,909 \text { of } 19,321 \\
(9.9 \%)^{*}\end{array}$ \\
\hline Mean Income, Families of All Applicants & $\$ 124,111$ & $\$ 120,015^{*}$ \\
\hline $1^{\text {st }}$ Percentile, Family Income of Applicants & $\$ 31,175$ & $\$ 29,075^{*}$ \\
\hline $\begin{array}{l}\text { 5th Percentile, Family Income of } \\
\text { Applicants }\end{array}$ & $\$ 46,989$ & $\$ 42,721 *$ \\
\hline $\begin{array}{l}10^{\text {th }} \text { Percentile, Family Income of } \\
\text { Applicants }\end{array}$ & $\$ 58,075$ & $\$ 53,236^{*}$ \\
\hline $\begin{array}{l}25^{\text {th }} \text { Percentile, Family Income of } \\
\text { Applicants }\end{array}$ & $\$ 83,342$ & $\$ 78,436^{*}$ \\
\hline $\begin{array}{l}\text { 50 }^{\text {th }} \text { Percentile, Family Income of } \\
\text { Applicants }\end{array}$ & $\$ 119,870$ & $\$ 115,929 *$ \\
\hline $\begin{array}{l}75^{\text {th }} \text { Percentile, Family Income of } \\
\text { Applicants }\end{array}$ & $\$ 156,242$ & $\$ 153,026^{*}$ \\
\hline
\end{tabular}

Notes: All incomes are put into 2004 equivalents so that the comparison of the Classes of 2008 and 2009 could be on an even basis. Only students whose families reside in the U.S. are included. An asterisk indicates that the amounts are significantly significant different with confidence at the 99 percent for the class of 2008 and 2009. 
Figure 3 and Table 3 compare the income distribution for the applicant pools in both years to the income distribution for students in the Search File. In the year prior to the Initiative, a larger percentage (2.4 percent) of searched students had incomes below $\$ 40,000$ than Harvard applicants did (1.9 percent). This means that Harvard attracts a disproportionately small number of applicants from students in the lowest range of incomes. After the Initiative, Harvard applicants had about the same likelihood (2.5 percent) of being in the lowest income range as the searched students.

Similarly, in the year prior to the Initiative, a larger percentage (31.7 percent) of searched students had incomes in the range between $\$ 40,000$ and $\$ 80,000$ than Harvard applicants did (23.1 percent), indicating that Harvard also attracts a disproportionately small number of applications from this second range of incomes. After the Initiative, 26.3 percent of Harvard's applicants came from families with income between $\$ 40,000$ and $\$ 80,000$. This is substantial progress, but Harvard still attracted a disproportionately small number of applicants from this range.

At the other end of the income distribution, Figure 3 and Table 3 also show that Harvard attracts a proportionate number of applications from students in the $\$ 80,000$ to $\$ 120,000$ income range and attracts a disproportionately large number of applicants from families with incomes above $\$ 120,000$. However, the disproportionality is not great, especially after the Initiative.

These numbers indicate that the increase in applications for Harvard's Class of 2009 was disproportionately from students from families with low incomes. Of course, the "extra" applicants were not all poor: if they had been, the number of applicants with incomes below \$40,000 would have quintupled between the Classes of 2008 and 2009. Nevertheless, the extra applicants did have somewhat lower incomes, which generate the downward shift in all measures of the affluence of Harvard's applicants, and suggests that the Financial Aid Initiative was successful in attracting exactly those applicants it targeted. 
Figure 3: "Available" Students and Applicants to the Classes of 2008 and 2009

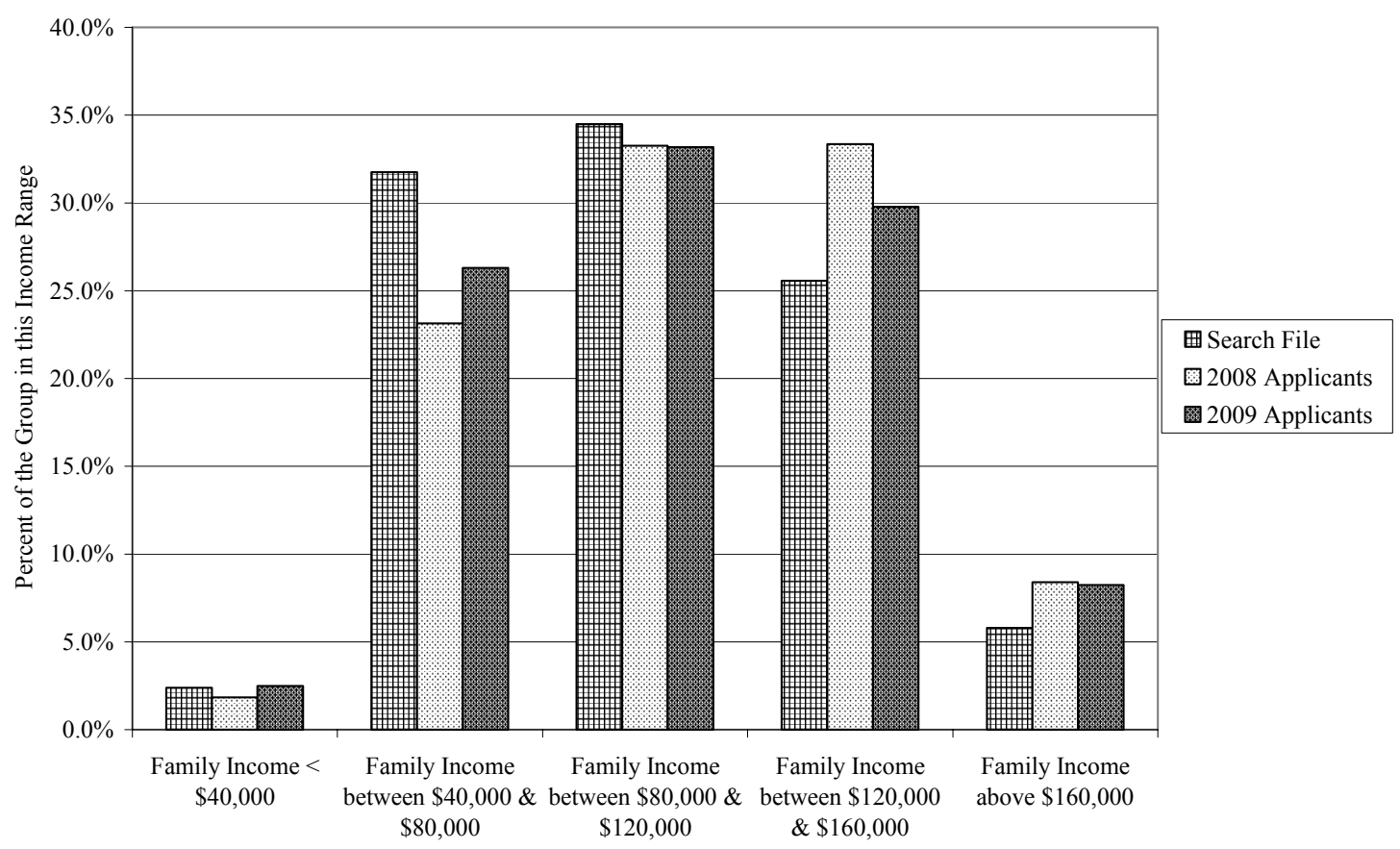

Table 3:

"Available" Students and Applicants, by Income Range

Search File

(Plausible

2008

2009

Family Income $<\$ 40,000$

Applicants)

Applicants

Applicants

Family Income between $\$ 40,000$ \&

$2.4 \%$

$1.9 \%$

$2.5 \%$

$\$ 80,000$

$31.7 \%$

$23.1 \%$

$26.3 \%$

Family Income between $\$ 80,000$ \&

$\$ 120,000$

$34.5 \%$

$33.3 \%$

$33.2 \%$

Family Income between $\$ 120,000$ \&

$\$ 160,000$

$\begin{array}{rrr}25.6 \% & 33.3 \% & 29.8 \% \\ 5.8 \% & 8.4 \% & 8.3 \%\end{array}$

Family Income above $\$ 160,000$

Notes: All incomes are put into 2004 equivalents so that the comparison of the Classes of 2008 and 2009 could be on an even basis. Estimated incomes are used for all the calculations so that the Search File and applicants were treated in a parallel fashion. Only students whose families reside in the U.S. are included.

\section{iii. The Admission Decision}

We found that the probability of admission for students in each income category fell by similar rates for the Class of 2009. With a 15 percent increase in applications for the Class of 2009, the admissions rate for the entire applicant pool had to fall by an analogous amount since that Harvard's entering class was the same size in both years. To compare the admissions rates by income level across the two years, we first adjust the probabilities of admission for the Class of 2008 to reflect the smaller pool of applicants in that year. ${ }^{15}$ Given this adjustment, there was little change in the probability of admission, 
for a student from any income range, between the Class of 2008 and the Class of 2009. More precisely, none of the differences in the probability of admission that are shown in Figure 4 and Table 4 are statistically significant from zero at conventional levels of confidence.

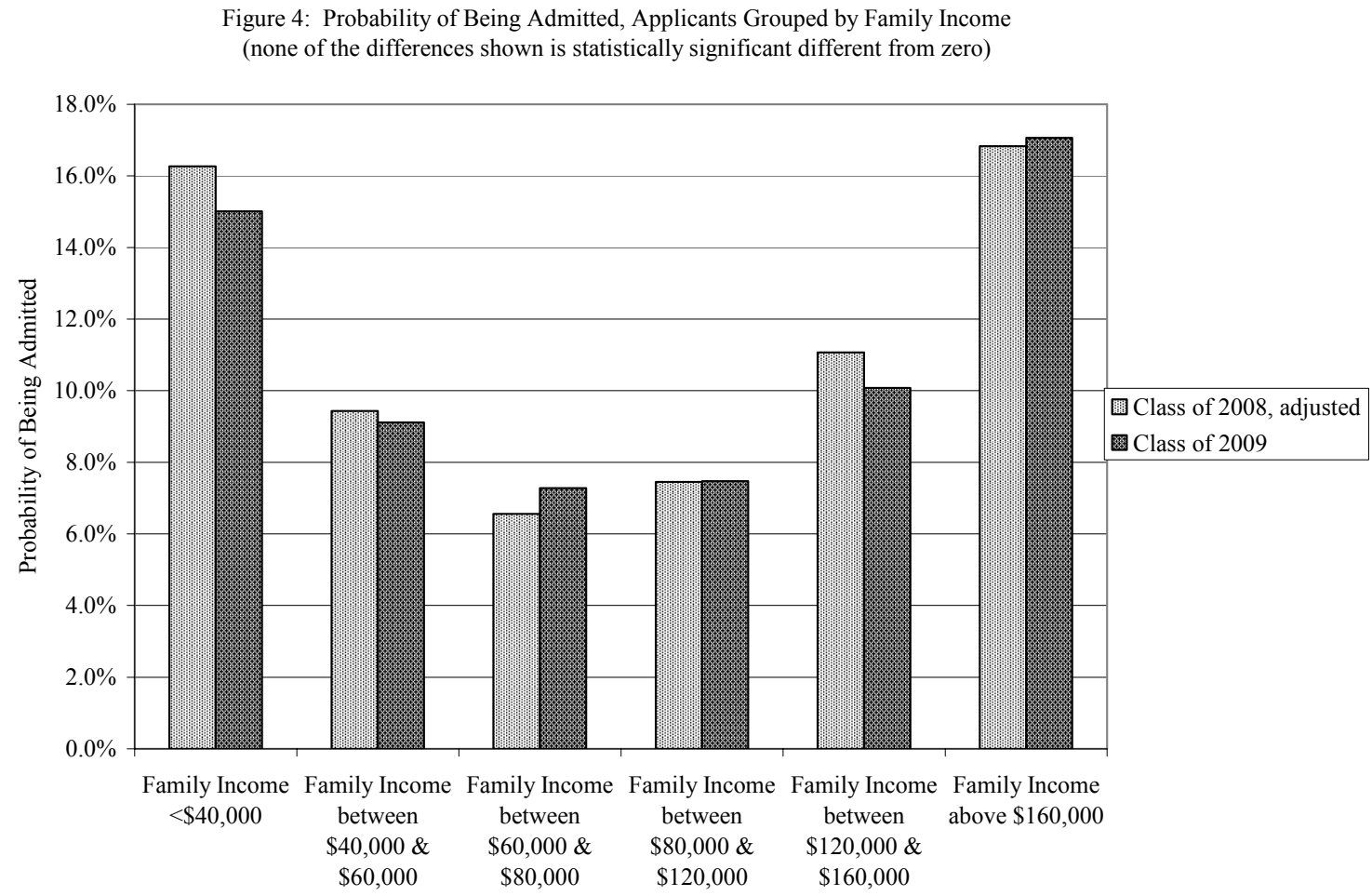

Table 4:

Probability of Being Admitted, Applicants to the Classes of 2008 and 2009 with adjustment for overall increase in applicants

(none of the differences between the two right-hand columns is statistically significant) Class of 2008,

Family Income $<\$ 40,000$

Family Income between $\$ 40,000 \& \$ 60,000$

Family Income between $\$ 60,000 \& \$ 80,000$

Family Income between $\$ 80,000 \& \$ 120,000$

Family Income between $\$ 120,000$ \& \$160,000

Family Income above $\$ 160,000$

Total: all Family Incomes
Class of 2008

$18.1 \%$

$10.5 \%$

$7.3 \%$

$8.3 \%$

$12.3 \%$

$18.8 \%$

$11.5 \%$ adjusted

$16.3 \%$

$9.4 \%$

$6.6 \%$

$7.5 \%$

$11.1 \%$

$16.8 \%$

$10.0 \%$
Class of 2009

$15.0 \%$

$9.1 \%$

$7.3 \%$

$7.5 \%$

$10.1 \%$

$17.1 \%$

$10.0 \%$

Notes: All incomes are put into 2004 equivalents so that the comparison of the Classes of 2008 and 2009 could be on an even basis. Only students whose families reside in the U.S. are included. The adjustment accounts for the overall increase in the number of applicants between the Classes of 2008 and 2009.

We have seen that the Financial Aid Initiative drew students from lower income families into Harvard's pool of applicants. Without information on admission decisions, however, we have limited ability to assess the quality of applications from the low income students who would not have applied prior to the Initiative. For example, if the 
Initiative only attracted new applicants from low income backgrounds who had poor qualifications and none of them could be admitted, then the admissions rate would have to fall disproportionately for the low income range to reflect the decline in the quality of applicants in that range.

Since we found that the admission rate fell by similar proportions across income categories after the introduction of the Initiative, it appears that the low income applicants who were attracted to apply by the Initiative had similar qualifications to the low income applicants who would have applied even without the Initiative. Indeed, a simple check of class rank and SAT scores shows that they remained almost constant for applicants in each income category. This indicates that Harvard may have expanded its applicant pool without weakening the quality of applicants.

However, admission to Harvard is not purely on the basis of class rank and SAT scores, and the new applicants may have been relatively weak in other areas, such as preparation in advanced material, demonstrations of leadership, or extracurricular activities. Indeed, the idea that disadvantaged students would be weak on such dimensions was the motivation of the third part of the Initiative. Thus, we think it reasonably likely that the Admissions Office intensified its analysis of applications from disadvantaged students to ensure that it maintained a similar admissions rate for low income students as in previous years (after adjusting for the overall increase in applications).

In short, the Financial Aid Initiative appears so far mainly to have affected the number and composition of Harvard's applicants. In particular, the relative increase in low income applicants also translated into a relative increase in low income admits for the Class of 2009.

\section{iv. The Matriculation Decision for Students}

We found that among admitted students from every income range, the probability of matriculating was the same for the Class of 2008 and the Class of 2009. More precisely, none of the differences in the probabilities of matriculating are statistically significantly different from zero.

Because the low income applicants who were attracted to apply by the Initiative were probably less drawn to Harvard and/or more financially constrained than others, the steady matriculation rates are interesting. They suggest that the Office of Admissions and Financial Aid did a good job of addressing the financial needs and other concerns of these new applicants.

An interesting fact to take away from Table 5 is the matriculation rate is highest at the two ends of the income distribution. Students from families with incomes below $\$ 40,000$ have about a 90 percent likelihood of matriculating, in both the 2008 and 2009 classes. ${ }^{16}$ The average matriculation rate for students from families with incomes above $\$ 160,000$ is 86 percent. Matriculation rates for students from families with incomes in the $\$ 60,000$ to $\$ 120,000$ range are considerably lower: 71 percent to 75 percent. The Ushaped pattern of matriculation probabilities suggests that students from middle income families have alternatives to Harvard that, cost considered, they prefer. This may be

\footnotetext{
${ }^{16}$ We note that the matriculation rates for the Class of 2008 may already reflect the influence of the Financial Aid Initiative, since the Initiative was announced between the application deadline and the date when students received financial aid packages for the Class of 2008.
} 
because middle income families contribute to the cost of Harvard education but pay little or nothing if their child attends their state's flagship university with a merit scholarship. Low income families, in contrast, pay similarly small amounts at Harvard and state universities. High income families receive little or no aid at Harvard but are also relatively insensitive to merit scholarships offered by less selective universities (which are often small in absolute size). For more discussion of families' reaction to tuition and aid packages, see Avery and Hoxby (2004).

Figure 5: Probability of Enrolling, Among Students who were Admitted (none of the differences is statistically significantly different from zero)

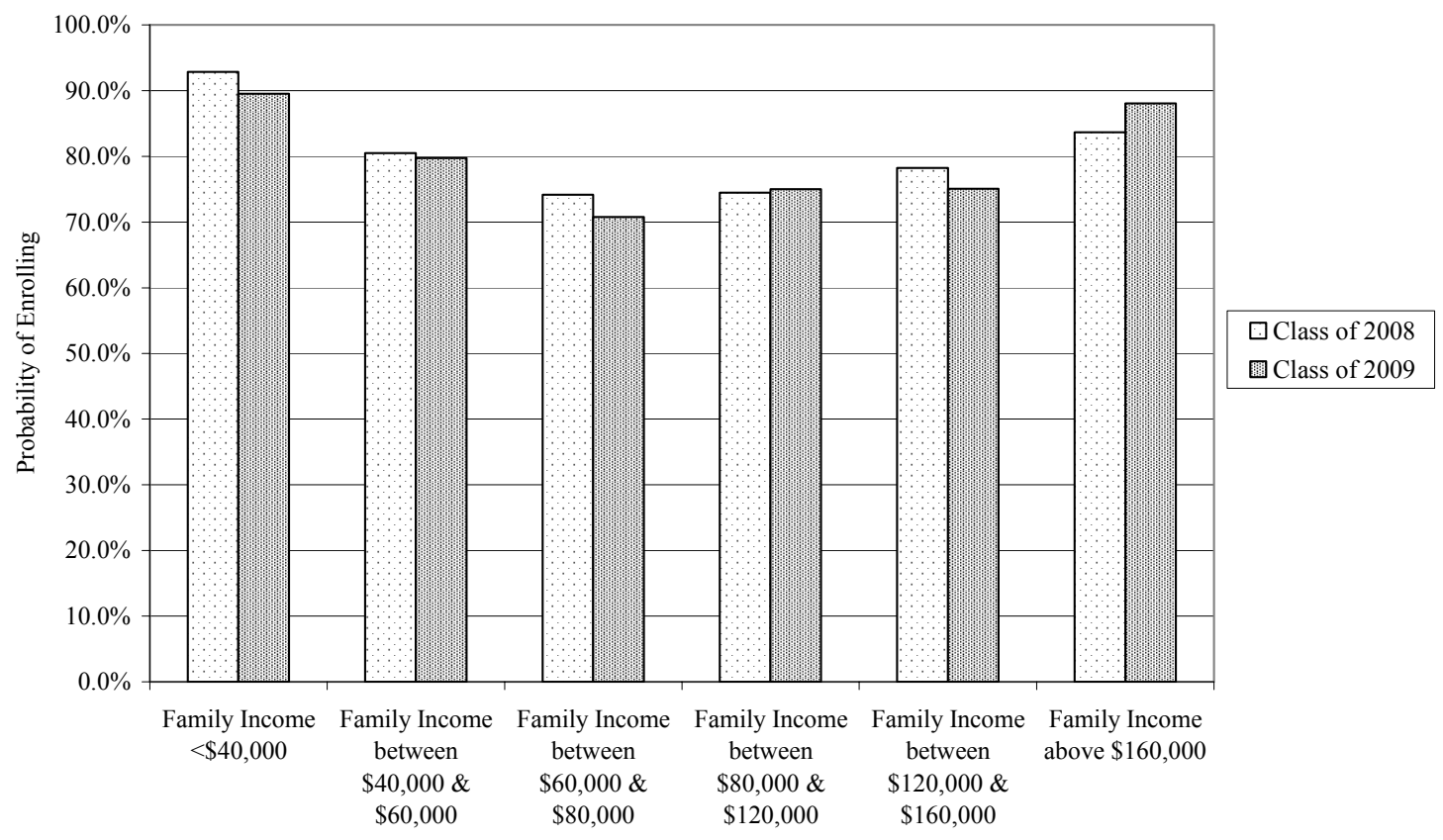

Table 5:

Probability of Enrolling, Among Students who were Admitted

Family Income $<\$ 40,000$ Class of 2008

Class of 2009

Family Income between $\$ 40,000 \& \$ 60,000$

$92.9 \%$

$89.5 \%$

$80.5 \%$

$79.8 \%$

Family Income between $\$ 60,000 \& \$ 80,000$

$74.1 \%$

$70.8 \%$

Family Income between $\$ 80,000$ \& \$120,000

$74.5 \%$

$75.0 \%$

Family Income between \$120,000 \& \$160,000

$78.2 \%$

$75.1 \%$

Family Income above $\$ 160,000$

$83.7 \%$

$88.1 \%$

$79.1 \%$

$78.7 \%$

Total: all Family Incomes

Notes: All incomes are put into 2004 equivalents so that the comparison of the Classes of 2008 and 2009 could be on an even basis. Only students whose families reside in the U.S. are included. 


\section{v. Summary of Results on Family Income}

What are we to conclude? First, the main reason why there are relatively few low income students enrolling at Harvard is that there are relatively few in the pool of plausible applicants (searched students). Therefore, only long-term policies that ameliorate the educational deficiencies of low income students can make the income distribution of Harvard students echo the income distribution of the population of U.S. students. We are necessarily referring here to government policy on elementary and secondary education because, though the Financial Aid Initiative does attempt to address long-term educational deficiencies, Harvard's scale is tiny relative to the U.S. and even the most successful Harvard policy could not possibly remedy national problems.

Second, the Initiative has significantly improved Harvard's recruiting of applicants from low income families, but further improvements should be possible, particularly in the recruiting of students from low-to-moderate income families $(\$ 40,000$ to $\$ 80,000)$. Students from this particular range of incomes $(\$ 40,000$ to $\$ 80,000)$ remain underrepresented in the pool of applicants relative to the set of potential applicants from the Search File.

Third, our findings reflect the fact that Harvard already offered quite generous financial aid packages to low income students before the introduction of the Initiative: the matriculation rates for low income students admitted to the Class of 2008 were actually higher than the matriculation rates for students from higher income ranges up to $\$ 160,000$. This suggests that Harvard has only limited ability to increase enrollment from low income students by competing more aggressively to enroll low income students who are admitted both to Harvard and to an attractive rival college.

On the whole, it seems to us that the Initiative affected the admissions process in exactly the right way. It drew students who were qualified but would otherwise have thought Harvard unaffordable into the pool of applicants. The extra students were treated fairly in the admissions process. They appear also to have had their financial needs met because the matriculation rate for low income students who were admitted was about the same in both years. Harvard's initial surmise had been that there existed a group of students whose "menus" did not include schools like Harvard solely because they did not know about its aid or were put off by the need to make even a modest contribution towards its cost. This group of students does evidently exist and they were unambiguously made better off as their menus expanded to include Harvard and possibly other selective private colleges as well.

Although the new financial aid packages were fully rolled-out in the first year of the Initiative, we expect the other parts of the Initiative (recruiting, analysis of disadvantage in the admissions process, summer school) to increase in efficaciousness over time. Thus, the first year effects, though significant in themselves, understate the likely long-run effects of the Initiative. 


\section{Is the Class of 2009 More Likely to be Disadvantaged, based on Indicators Other than Family Income?}

Having made a careful study of family income, we now more briefly examine other indicators of disadvantage for applicants, admittees, and matriculants to the Classes of 2008 and 2009: 1) parental education; 2) neighborhood of residence; 3) high school history of applicants and admits to Harvard.

\section{i. Parental Education}

It is useful to examine parents' educational attainment, partly because it indicates the likely degree of sophistication about selective colleges in a student's home and partly because it is a good indicator of wealth (that is, parents' education is more closely associated with a family's usual income than with its income in a single year).

Table 6 shows that applicants to the Class of 2009 were statistically significantly more likely to have parents neither of whom had a college education ( 2 percent more likely) or to have only parent with a college education (1 percent more likely). Applicants to the Class of 2009 were also statistically significantly less likely to have at least one parent who held a graduate degree (3 percent more likely). Similar differences show up among students who were admitted to or enrolled in the Class of 2009. Compared to their counterparts in the previous Class, they were statistically significantly more likely to have at least one parent with no college education and less likely to have at least one parent with a graduate degree.

These findings mirror the results based on incomes. Where Table 1 indicated that the percentage of enrolled students qualifying for the Financial Aid Initiative based on family income increased from $14.8 \%$ for the Class of 2008 to $16.6 \%$ for the Class of 2009, Table 6 indicates that the percentage of enrolled students with at least one parent who did not graduate from college increased from $16.8 \%$ for the Class of 2008 to $19.5 \%$ for the Class of 2009.

Table 6:

Parents' Educational Attainment, Classes of 2008 and 2009

Applied Admitted Enrolled

\begin{tabular}{|c|c|c|c|c|c|}
\hline $\begin{array}{c}\text { Class of } \\
2008\end{array}$ & $\begin{array}{c}\text { Class of } \\
2009\end{array}$ & $\begin{array}{c}\text { Class of } \\
2008\end{array}$ & $\begin{array}{c}\text { Class of } \\
2009\end{array}$ & $\begin{array}{c}\text { Class of } \\
2008\end{array}$ & $\begin{array}{c}\text { Class of } \\
2009\end{array}$ \\
\hline $9.9 \%$ & $12.0 \% *$ & $7.4 \%$ & $8.3 \%$ & $7.6 \%$ & $8.7 \%$ \\
\hline $9.0 \%$ & $10.0 \% *$ & $5.5 \%$ & $7.3 \% *$ & $5.4 \%$ & $7.2 \% *$ \\
\hline $5.2 \%$ & $5.3 \%$ & $3.6 \%$ & $3.9 \%$ & $3.8 \%$ & $3.6 \%$ \\
\hline $17.0 \%$ & $16.9 \%$ & $13.0 \%$ & $12.5 \%$ & $13.5 \%$ & $12.8 \%$ \\
\hline $27.5 \%$ & $25.8 \% *$ & $26.2 \%$ & $26.8 \%$ & $25.9 \%$ & $25.9 \%$ \\
\hline $31.5 \%$ & $30.1 \% *$ & $44.4 \%$ & $41.2 \% *$ & $43.9 \%$ & $41.8 \%$ \\
\hline
\end{tabular}

$31.5 \%$
Both have no college

One has undergraduate

school, one no college

One has graduate school, one

no college

Both have undergraduate

school

One has undergraduate, one

graduate school

Both have graduate school

Notes: An asterisk indicates that the values are statistically significantly different from zero with 95 percent confidence for the Classes of 2008 and 2009. Only students whose families reside in the U.S. are included. 


\section{ii. Neighborhood of Residence}

We also compare the neighborhoods from which the Classes of 2008 and 2009 were drawn. As shown in Table 7, we find that applicants to the Class of 2009 came from neighborhoods that have a variety of characteristics associated with financial disadvantages and lower propensities to attend selective colleges. For instance, the 2009 applicants came from neighborhoods that had lower median family incomes, a greater share of families with incomes below $\$ 40,000$, lower median house values, a greater share of homes valued at less than $\$ 100,000$, a smaller share of adults with a college degree, and a larger share of the population belonging to a racial or ethnic minority group. ${ }^{17}$ Applicants to the Class of 2009 also came from secondary schools (both public and private) in which racial and ethnic minorities formed a larger share of the student body. All of these differences are statistically significant at the $90 \%$ level of confidence. When we compare the Classes of 2008 and 2009 in terms of 1) admitted students and 2) matriculating students, we find smaller but otherwise similar differences in neighborhoods of residence. For admitted and enrolled students, only some of the differences are statistically significant, but we see an overall picture that is consistent with the results on students' family incomes. Members of the class of 2009 were a few percentage points more likely to come from a neighborhood with characteristics that are not propitious for enrollment in selective colleges like Harvard.

\footnotetext{
${ }^{17}$ Home values are an important measure of wealth, and - since home equity is an important source of collateral - an indicator of a family's ability to obtain loans to pay for college education. We define racial and ethnic minorities as all people who are not white and non-Hispanic.
} 
Table 7:

Characteristics of Students' Neighborhoods, Classes of 2008 and 2009

\begin{tabular}{|c|c|c|c|c|c|c|}
\hline & \multicolumn{2}{|c|}{ Applied } & \multicolumn{2}{|c|}{ Admitted } & \multicolumn{2}{|c|}{ Enrolled } \\
\hline & $\begin{array}{l}\text { Class of } \\
2008\end{array}$ & $\begin{array}{l}\text { Class of } \\
2009\end{array}$ & $\begin{array}{l}\text { Class of } \\
2008\end{array}$ & $\begin{array}{l}\text { Class of } \\
2009\end{array}$ & $\begin{array}{l}\text { Class of } \\
2008\end{array}$ & $\begin{array}{l}\text { Class of } \\
2009\end{array}$ \\
\hline $\begin{array}{l}\text { Median Family Income in } \\
\text { Neighborhood } \\
\text { Percent from a }\end{array}$ & $\$ 77,393$ & $\$ 74,294 *$ & $\$ 81,980$ & $\$ 79,924^{*}$ & $\$ 82,343$ & $\$ 80,570$ \\
\hline Neighborhood in which & & & & & & \\
\hline $\begin{array}{l}\text { Median Income }<\$ 40,000 \\
\text { Median Home Value in }\end{array}$ & $13.4 \%$ & $16.2 \% *$ & $13.1 \%$ & $14.6 \%$ & $12.8 \%$ & $14.6 \%$ \\
\hline $\begin{array}{l}\text { Neighborhood } \\
\text { Percent from a } \\
\text { Neighborhood in which } \\
\text { Median Home Value }\end{array}$ & $\$ 263,855$ & $\$ 254,244^{*}$ & $\$ 297,279$ & $\$ 287,767$ & $\$ 301,597$ & $\$ 295,271$ \\
\hline $\begin{array}{l}<\$ 100,000 \\
\text { Percent of Adults in } \\
\text { Neighborhood with a }\end{array}$ & $11.1 \%$ & $12.8 \% *$ & $10.1 \%$ & $12.3 \% *$ & $9.5 \%$ & $11.4 \% *$ \\
\hline $\begin{array}{l}\text { College Education } \\
\text { Percent of Neighborhood } \\
\text { Population who are }\end{array}$ & $47.1 \%$ & $44.8 \% *$ & $51.6 \%$ & $49.6 \% *$ & $51.8 \%$ & $49.5 \% *$ \\
\hline $\begin{array}{l}\text { Racial/Ethnic Minorities } \\
\text { Percent of Peers in Student's } \\
\text { School who are }\end{array}$ & $23.6 \%$ & $25.4 \% *$ & $22.1 \%$ & $23.0 \%$ & $21.3 \%$ & $22.5 \%$ \\
\hline Racial/Ethnic Minorities & $29.9 \%$ & $30.9 \% *$ & $28.1 \%$ & $28.5 \%$ & $27.6 \%$ & $28.1 \%$ \\
\hline
\end{tabular}

\section{IV. "One-Offs"}

Many low to moderate income students in the United States come from regions and schools that do not have strong traditions of sending students to selective colleges in the Northeast, like Harvard. As a result, these students may lack information on how to get through the admissions process, what aid to expect, and what a Harvard education is like. If The College is to reach substantially greater numbers of students from disadvantaged backgrounds, it will need to recruit students from schools that have sent applicants to Harvard only occasionally in the past, if at all. Note that some schools, especially "exam" schools such as Stuyvesant in New York City and the North Carolina School of Science and Math, are traditional "feeders" and yet have substantial shares of their student populations coming from low to moderate income families. It is our view, however, that such schools experienced major recruiting efforts before the initiative and are unlikely to be a source of qualified, low income students who need to be reached.

We classify high schools by their history with Harvard in terms of sending applications, getting students admitted, and having students enroll. Our history variables 
use information from the admissions process for the five Classes before the two we study - that is for the Classes of 2003 to 2007.

Table 8 provides a sense of the importance of school history. While 56 percent of potential students (those in the Search File) come from schools that had between 10 or more students apply to Harvard in the previous five years, 68 percent of the applicants and 79 percent of matriculants came from these schools. At the other end of the spectrum, 9 percent of potential students come from schools that had sent no applications to Harvard in the previous five years, but only 2.8 percent of those enrolling in the Class of 2008 came from such schools.

Table 8:

School "Histories" with Harvard, Illustrated by the Class of 2008

$\begin{array}{ccccc}\begin{array}{c}\text { Number of } \\ \text { Applications to } \\ \text { Harvard in the } \\ \text { Last 5 Years }\end{array} & \begin{array}{c}\text { Percent of Available } \\ \text { Students who Fit into } \\ \text { this Category (from } \\ \text { Search File) }\end{array} & \begin{array}{c}\text { Students who } \\ \text { Applied to the } \\ \text { Class of }\end{array} & \begin{array}{c}\text { Students } \\ \text { Admitted to } \\ \text { the Class of }\end{array} & \begin{array}{c}\text { Students who } \\ \text { Enrolled in } \\ \text { the Class of }\end{array} \\ \text { 0 } & 9.0 \% & 5.1 \% & 2008 & 2008 \\ 1 \text { to } 2 & 10.2 \% & 6.8 \% & 2.8 \% & 2.8 \% \\ 3 \text { to } 5 & 11.5 \% & 8.2 \% & 4.0 \% & 4.1 \% \\ 6 \text { to } 10 & 13.7 \% & 12.0 \% & 5.8 \% & 5.4 \% \\ 11 \text { to } 30 & 27.2 \% & 28.7 \% & 26.8 \% & 8.9 \% \\ 31 \text { to } 50 & 12.5 \% & 15.6 \% & 17.5 \% & 27.4 \% \\ 51 \text { to } 100 & 8.6 \% & 11.9 \% & 16.5 \% & 17.5 \% \\ 101 \text { or more } & 7.3 \% & 11.8 \% & 17.7 \% & 17 \% \\ \text { NOTE: This table includes only students whose families resided in the United States. Percentages in } \\ \text { each column may not add to } 100 \% \text { due to rounding. }\end{array}$

Another way to think about the importance of a school's history is to consider the number of schools that were represented in the search file. For the Class of 2008, 10,555 high schools had at least one student in the Search File but only 5,368 schools sent at least one application to Harvard. This suggests that there are more than 5,000 high schools where Harvard could hope to attract applicants but no students applied. High schools with little prior history of applying to Harvard tend to have a disproportionate number of disadvantaged students. For example, more than 10 percent of the students at schools with limited prior history of applying to Harvard qualify for free or reduced price lunch. By contrast, fewer than 5 percent of students at schools averaging 10 or more applications to Harvard qualify for free or reduced price lunch.

In short, an important question is whether the Financial Aid Initiative expanded the set of schools that are developing a "history" with Harvard. We find evidence that it did, largely because the extra applicants to the Class of 2009 disproportionately came from schools that had a slight or no admissions history. These results are shown in Figure 6 and Table 9. For instance, 5.1 percent of applicants to the Class of 2008 came from schools that had sent no applications to the Classes of 2003 through 2007, but 6.8 percent of applicants to the Class of 2009 came from such schools. 34.1 percent of applicants to the Class of 2008 came from schools that had no student enrolled in the Classes of 2003 through 2007, but 37.6 percent of applicants to the Class of 2009 came from such schools. Figure 6 shows a consistent pattern: the Class of 2009 came from 
schools that had fewer past applications, admitted students, and enrolled students than the Class of 2008. Nevertheless, we can see that additional progress in expanding the reach of recruiting is possible: compare the available students and the Class of 2009 in Figure 6.

Figure 6: Available Students and Harvard's Recruiting for the Classes of 2008 \& 2009

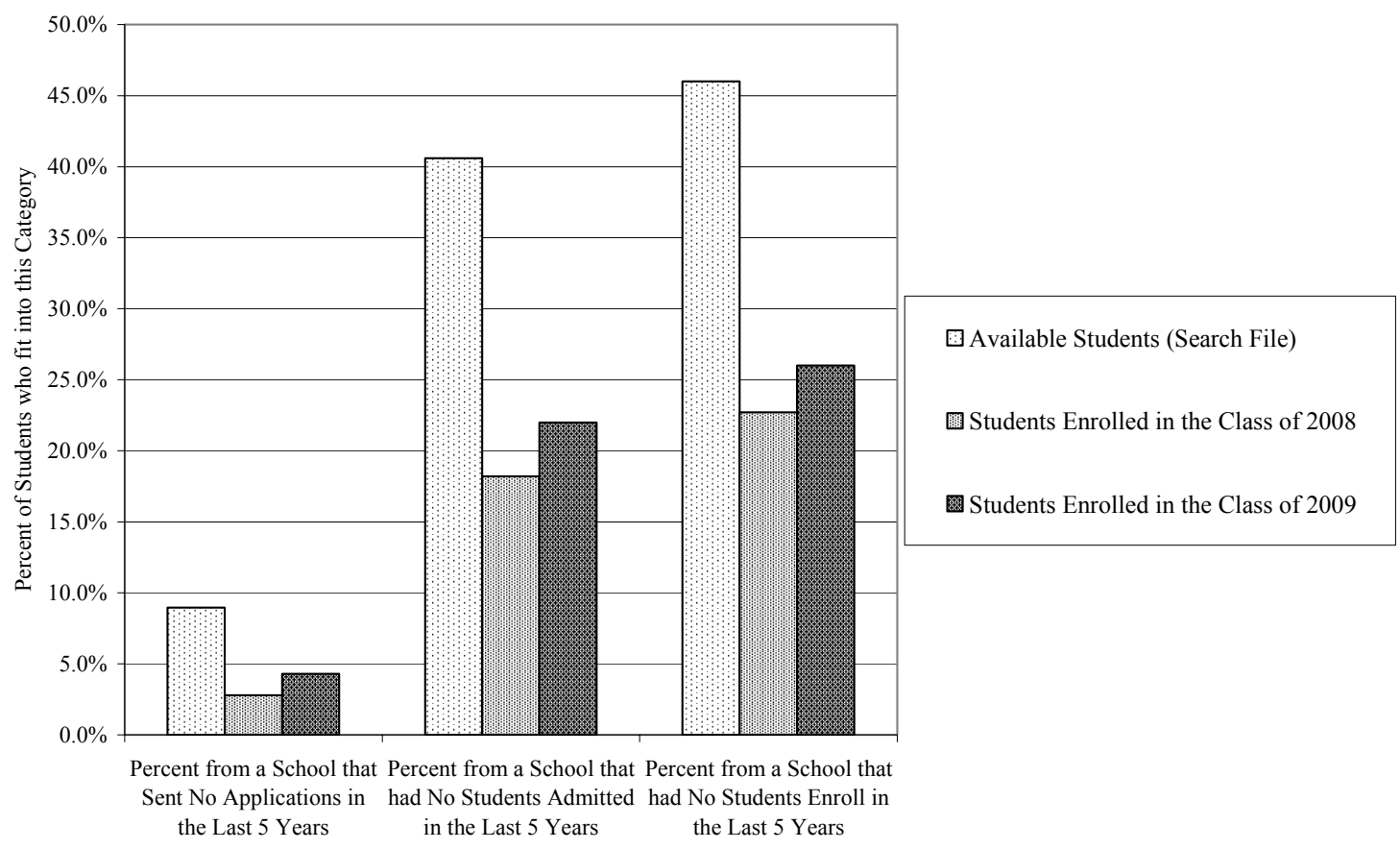

How does a selective private college create effective outreach to students who are "one-offs" - that is, students who attend a high school that has sent no or few students (or even applications) in the recent past? Traditional methods of outreach include high school visits and local open houses, but these methods will have low efficacy with oneoffs. Simply because a high school has a qualified applicant this does not guarantee that it will have one next year or the year after: this is the essence of a student's being a oneoff. Thus, many school visits would potentially be wasted: admissions officers cannot possibly visit all U.S. high schools so that many schools would necessarily be visited in the "wrong" year and enjoy no visit in the "right" year. Instead, it is logical simply to match application, admittance, and enrollment histories to the students in the search file, identify the one-offs, and direct targeted recruitment efforts to them: telephone calls from current students, emails, and specialized materials designed for students like them. The specialized efforts should presumably be designed to compensate for the counseling and informal advice that they lack because they are isolated. 
Table 9:

Changes in the Harvard's Recruiting for the Classes of 2008 and 2009, Students Categorized by their School's Admissions "History"

\begin{tabular}{ccccccc} 
Available & \multicolumn{2}{c}{ Applicants } & \multicolumn{2}{c}{ Admitted } & \multicolumn{2}{c}{ Enrolled } \\
Students & Class & Class & Class & Class & Class & Class \\
(Search & of & of & of & of & of & of \\
File) & 2008 & 2009 & 2008 & 2009 & 2008 & 2009
\end{tabular}

Number of Applications

from Student's School in

the Last 5 Years

32

45

42

64

59

65

59

Percent from a School that

Sent No Applications in

the Last 5 Years

$9.0 \%$

$5.1 \%$

$6.8 \%$

$2.8 \%$

$4.3 \%$

$2.8 \%$

$4.3 \%$

Number Admitted from

Student's School in the

Last 5 Years

5

Percent from a School that

had No Students Admitted

in the Last 5 Years

$40.6 \%$

$29.2 \%$

$32.8 \%$

$17.7 \%$

$22.0 \%$

$18.2 \%$

$22.0 \%$

Number Enrolled from

Student's School in the

Last 5 Years

4

6

6

11

10

11

10

Percent from a School that

had No Students Enroll in

the Last 5 Years

$46.0 \%$

$34.1 \%$

$37.6 \%$

$22.2 \%$

$26.4 \%$

$22.7 \%$

$26.0 \%$

\section{Conclusions}

Our analyses produce consistent positive findings for the effects of the first year of the Financial Aid Initiative. Enrollment of students qualifying for the Initiative increased by $11 \%$ in one year; enrollment of students with family incomes below $\$ 40,000$ increased by nearly $20 \%$. The most conspicuous effect of the Financial Aid Initiative was that it attracted applications from students who qualified for it. After the introduction of the initiative, the percentage of applicants from families with incomes of $\$ 40,000$ or below jumped by more than $20 \%$. In fact, among potential applicants to Harvard (those appearing in The College Board Search File), those from families with very low incomes and those from families with very high incomes were about equally likely to apply.

For both the Class of 2008 and 2009, applicants from low income families were about equally likely as applicants from high income families to be admitted to Harvard and to enroll. This indicates that the Admissions Office has been able to correct for differences in resources and extracurricular opportunities in evaluating applications. It also indicates that Harvard's financial aid packages do make it possible for students from all backgrounds to attend Harvard; the publicity surrounding the Financial Aid Initiative 
may have masked the fact that Harvard was already providing substantial financial aid to students whose families could not afford the college's full costs.

Some commentators, when considering the Initiative, expected that it would create a new form of affirmative action. This expectation does not seem to have been realized. There appears to be an untapped pool of qualified applicants whose family incomes are more diverse than those of past applicants.

Looking forward, while we find that the Financial Aid Initiative was successful in its first year, the underlying challenge is that the set of Harvard's potential applicants is disproportionately wealthy relative to the population. For Harvard to further increase its enrollment of low income students in the short-run, it will have to reach ever further into the untapped pool mentioned above. The students in this pool are, however, disproportionately "one-offs." That is, they are widely dispersed and many of them attend schools that have never had anyone apply to Harvard. This suggests that recruiting efforts that specifically target one-offs, who can be identified because their schools have little or no "Harvard history," may be more productive than recruiting efforts that are broadly directed toward disadvantaged students. 